Classification

Physics Abstracts

$61.16 \mathrm{D}-61.04 \mathrm{D}-91.40$

\title{
Preparative Method and Analysis by OM, SEM and EPMA of Porous, Brittle and Low Permeability Rocks and Materials: The Case of Pumices
}

\author{
Fabio Gamberini $\left({ }^{1}\right)$ and Giovanni Valdrè $\left({ }^{1,2, *}\right)$ \\ $\left.{ }^{1}\right)$ Dept. of Mineralogical Sciences, P. Porta San Donato 1, University of Bologna, 40126 Bologna, \\ Italy \\ $\left({ }^{2}\right)$ Electron Microscopy Centre - INFM, University of Bologna, 40126 Bologna, Italy
}

(Received 23 March; accepted 20 April, 1995)

\begin{abstract}
A method is reported for the preparation of flat specimens (30 $\mu \mathrm{m}$ thick) of porous, brittle and low permeability materials and rocks for both optical microscopy $(\mathrm{OM})$, scanning electron microscopy (SEM) and electron probe microanalysis (EPMA). The method, based on alternating embeddings in vacuum with epoxy resin and grindings with final polishing down to $0.25 \mu \mathrm{m}$ alumina grain size, prevents the breaking of the glassy interconnections and fills with resin the majority of the bubbles and voids. It has been applied to the analysis of pumices sampled at Linosa, Sicily, which are glassy materials with inhomogeneities on a micro-scale and with a vesicular texture often not interconnected. The method has been successfully applied also to the preparation of various sedimentary rocks, synthetics, bones and biomaterials.
\end{abstract}

\section{Introduction}

During the preparation of thin mineral sections for transmitted-light optical microscopy (OM), major difficulties arise when embedding samples with poor lithification or samples with a high degree of consolidation, high porosity with cells not initerconnected, hence a permeability almost absent. In this case impregnation takes place only in a surface layer of the sample. The preparative method becomes more demanding if the same sample must be used also for Scanning Electron Microscopy (SEM) observations and for EDS or WDS microanalysis; in this case the morphology obtained by $\mathrm{OM}$ must be complemented with the microchemistry, to grain information on the genesis and/or the transformation the material has undergone.

The present paper describes, for the first time to our knowledge, a general preparation method for fragile, high porosity and low permeability samples for both observation by OM and SEM equipped for quantitative EDS microanalysis, and/or for Electron Probe Micro-Analysis (EPMA) with WDS.

$\left(^{*}\right)$ Author to whom correspondence should be sent. 
The method has been successfully applied to the preparation of pumices sampled at Linosa, Sicily (Italy).

Similar preparative methods for OM observations usually refer to unconsolidated fine-grained sediments [1-3], soils and clay-rich samples [4,5] and to friable wafers from clastic sedimentary rocks for fluid inclusion analysis [6].

Pumices are pyroclastic rocks produced by bursts of magmatic material in the air during the first stages of explosive volcanism involving large amount of gases. They are glassy materials of sialic composition with inhomogeneities on a micro-scale and with vesicular textures very rich in bubbles and voids, often not interconnected. The size and density of the gas bubbles is such that the specific gravity, in some cases, is about $0.7 \mathrm{~g} / \mathrm{cm}^{3}$.

By using OM, SEM and EPMA, important magmatic information can be gathered from the knowledge of the crystal-chemistry and habit on a micro-scale.

For the above-mentioned analyses, the specimens must satisfy the following requirements:

i) for OM analysis, the material has to be prepared in thin sections (about $30 \pm 2 \mu \mathrm{m}$ ), polished at least with $1 \mu \mathrm{m}$ grit, over areas several $\mathrm{mm}^{2}$ large;

ii) for SEM analysis (secondary electrons SE, backscattered electrons BS, and cathodoluminescence $\mathrm{CL}$ ), the specimen has to be surface polished with at least $0.25 \mu \mathrm{m}$ grit over areas several $\mathrm{mm}^{2}$ large;

iii) for quantitative EDS or EPMA analysis, the material must have a surface polished with $0.25 \mu \mathrm{m}$ grit, a thickness not below $30 \mu \mathrm{m}$ and areas of some $\mathrm{mm}^{2}$.

In addition, for ii) and iii) the specimen must be electrically-conductive at the surface, which is achieved, in particular for quantitative microanalysis, by means of a carbon coating not thicker than $30 \mathrm{~nm}$.

\section{Description of the Sample Preparation Method}

The purpose of the preparation method is to obtain thin sections of pumice-rocks suitable for both observation by OM and by SEM and quantitative microanalysis (EDS or WDS).

The preparation method can be divided into three steps:

1) initial preparation and consolidation of the sample;

2) series of embeddings alternated to lapping;

3) final preparation of the specimen for the various types of observation.

The preparation of these samples requires the use of embedding and surface impregnation techniques. Since there is a lack of information on the preparation of pumices, it was necessary to try different embedding materials to choose the most suitable for each step of the work. The physico-chemical characteristics of the experimented embedding resins are summarized in the following and, in a condensed from, in Table I.

\subsection{EMBEDDING RESINS.}

2.1.1 Polyacrylic Resins. - They are mainly used for biological specimens, are soluble in alcohols and ketones, and their viscosity is about $100 \mathrm{cP}\left(1 \mathrm{P}=10^{-1} \mathrm{~Pa} . \mathrm{s}\right)$ at $25^{\circ} \mathrm{C}$. Polyacrylic resins polymerize both by heat treatment and by ultra-violet irradiation. Their thermal resistance is low and moreover, the deformations (changes in specific volume) can be high. For these reasons they are not suitable for series of embeddings. Worth noting is Lowicryl $\mathrm{K} 4 \mathrm{M}$ which can polymerize at temperatures below $0{ }^{\circ} \mathrm{C}$, hence can be used for the cryofixing and cryosubstitution of hydrated clay minerals. 
Table I. - List of embedding materials tested in the present work.

\begin{tabular}{|l|l|l|l|l|}
\hline Product & Producer & Type of Polymer & Components & Hardening conditions \\
\hline Acryfix & Struers & Polyacrylic & Powder+liquid & 15 minutes $\left(20^{\circ} \mathrm{C}\right)$ \\
Histo-resin & Reichert-Jung & Polyacrylic & Powder+liquid & 2 hours $\left(20^{\circ} \mathrm{C}\right)$ \\
Lowicryl-K4M & Lowicryl & Polyacrylic & 2 liquids & UV irradiation $\left(\lambda=360 \mathrm{~nm},-35^{\circ} \mathrm{C}, 24\right.$ hours $)$ \\
Sampl-Kwick & Buehler & Polyacrylic & Powder+liquid & 5 minutes $\left(20^{\circ} \mathrm{C}\right)$ \\
Technovit 4004 & Kulzer & Polyacrylic & Powder+liquid & 6 minutes $\left(20^{\circ} \mathrm{C}\right)$ \\
& & & & \\
Serifix & Struers & Polyester & 2 liquids & 40 minutes $\left(20^{\circ} \mathrm{C}\right)$ \\
Top-Polyresin & Pabisch & Polyester & Posder+liquid & $20-30$ minutes $\left(20^{\circ} \mathrm{C}\right)$ \\
Top-Transparesin & Pabisch & Polyester & 2 liquids & $20-30$ minutes $\left(20^{\circ} \mathrm{C}\right)$ \\
Epo-Kwick Epoxy & Buehler & Epoxy & 2 liquids & 30 minutes $\left(20^{\circ} \mathrm{C}\right)$ \\
Epofix & Struers & Epoxy & 2 liquids & 8 hours $\left(20^{\circ} \mathrm{C}\right)$ \\
Epoxy-Pack 301 & Logitech & Epoxy & 2 liquids & 12 hours $\left(20^{\circ} \mathrm{C}\right)$ \\
Top-Eporesin & Pabisch & Epoxy & 2 liquids & 6 hours $\left(20^{\circ} \mathrm{C}\right)$ \\
AW106-HV953u & Ciba-Geigy & Araldit (Epoxy) & 2 viscous liquids & 15 hours $\left(20^{\circ} \mathrm{C}\right)-5$ minutes $\left(150^{\circ} \mathrm{C}\right)$ \\
BY158-HY299b & Ciba-Geigy & Araldit (Epoxy) & 2 liquids & 48 hours $\left(5^{\circ} \mathrm{C}\right)-24$ hours $\left(20^{\circ} \mathrm{C}\right)$ \\
LY554-HY956 & Ciba-Geigy & Araldit (Epoxy) & 2 liquids & 24 hours $\left(20^{\circ} \mathrm{C}\right)$ \\
\hline
\end{tabular}

2.1.2 Polyesters. - These plastic materials have viscosity of about $900 \mathrm{cP}$ at $25^{\circ} \mathrm{C}$, their monomers are soluble in ketones. They polymerize in-toto and very rapidly, with low deformations. The polymers have high thermal resistance and are practically insoluble. The technical characteristics of these materials seem suitable for embeddings but they can polymerize also by means of light and oxygen; hence, they are rot stable and scarcely preservable.

2.1.3 Epoxy Resins. - The viscosity of epoxy resins is extremely variable (from 10 to $50000 \mathrm{cP}$ ); their monomers are soluble in ketones, esters and chlorinated solvents. They present very low deformations on curing, which depend on the polymerization temperature. These resins polymerize in-toto by means of hardening agents and in some cases the polymerization is fast. Epoxy resins, like polyesters, are practically insoluble when polymerized and present a good thermal resistance. Their use is widespread, although their development is more recent than for the other types of embedding materials. The preservability is good. They have been found to be the most suitable resin for the series of alternating embeddings described in this work.

2.2 First Step: Initial Preparation and Consolidation of the Sample. - For embedding the various types of specimens a vacuum chamber with variable pressure (minimum $5 \times 10^{-3}$ torr) equipped with a heating stage capable of reaching $200^{\circ} \mathrm{C}$ was used. A refrigerating cell $\left(2-4{ }^{\circ} \mathrm{C}\right)$ is also used to slow down the polymerization.

The pumices, in nature, are commonly found either:

(i) in the compact form with fragile texture and with very variable sizes (ranging between a few cms to $10 \mathrm{~cm}$ in diameter) or

(ii) in the form of sands and sediments.

Type (i) samples are coated with resin to provide a robust external supporting layer. Then the specimens are cut, if of large size, into small blocks of about $50 \times 30 \times 30 \mathrm{~mm}^{3}$ by means of a wheel saw, for easy-handling during the subsequent steps of preparation. The sizes of the cuts were deliberately kept much greater than those the specimen will have after the final preparation, 
when it will be about $30 \mu \mathrm{m}$ thick, and glued onto a circular glass support ( $25.4 \mathrm{~mm}$ in diameter) commonly used in EPMA and analytical SEM. The reason being to avoid, or at least to reduce, the propagation of fractures and structural deformations inside the sample induced by the wheel saw.

Small-sized samples (a few cms), which cannot be cut in the sizes of the blocks, are totally embedded in resin, then they are cut in sizes comparable to those of a typical rectangular glass slide $\left(28 \times 46 \mathrm{~mm}^{2}\right)$.

In general, before the various cuts, it is important to choose a priori the region, inside the pumice-rock, to be studied. The rough wheel cuts must be performed at least $2 \mathrm{~mm}$ away from the desired area to avoid the propagation of fractures.

These embeddings are performed at a pressure relatively low (about 100 torr), since the specimens have only to be prepared for easy-handling for the successive steps. Embeddings performed at higher vacuum $\left(5 \times 10^{-3}\right.$ torr $)$ could cause the breaking or fracture of internal structures of the specimen. The resin is pre-heated at about $80^{\circ} \mathrm{C}$ to increase its fluidity, hence to facilitate the surface impregnation of the sample.

Type (ii) samples, i.e., fragments and/or sands produced by the disgregation of pumices, are placed, in amount of $20-30 \mathrm{~g}$, in polyethylene containers of sizes $30 \times 30 \times 30 \mathrm{~mm}^{3}$ and successively embedded in resins. Since epoxy resins do not stick to polyethylene it will be easy to remove the embedded material from the container. Care should be exercised that the embedding takes place without (or with limited) formation of air bubbles in the resin and between resin and the pumice fragments. To this purpose the embedding can be directly performed at about $5 \times 10^{-3}$ torr and at $80^{\circ} \mathrm{C}$, since the sample is made of sediments and its structure is easily preserved. The evacuation of the vacuum-chamber must be performed very slowly in order to avoid the boiling off of the monomer out of the container due to rapid outgassing. It is convenient to outgas the resin before the sample is placed in it to avoid or minimize the air bubble formation during the successive steps.

For both cases (i) and (ii), the choice of a resin of low viscosity is therefore very important. In this work we have tested several resin (see Tab. I) and the most suitable one is Araldit BY158 with hardener HY229b. For specimen of lower fragility and higher permeability than pumices, Araldit LY554 with hardener HY956 can be also recommended.

One has to bear in mind that Araldit can react at high temperature with exothermal reaction. To avoid this, the specimens must be extracted from the vacuum chamber before polymerization takes place. In some cases, it is necessary to cool the specimens at $2-4{ }^{\circ} \mathrm{C}$ in a refrigerating cell. The cooling slows down the polymerization and therefore prevents the specimen structural deformations, which may occur otherwise.

It is useful, although not essential, to use vacuum-chambers equipped with devices for pouring the resin onto the sample under vacuum and at a controlled temperature. This is very effective for samples of high permeability since it is possible to outgas the resin before the embedding, without venting the vacuum-chamber. Embedding performed in this way produces the best results: very few air bubbles are present in the resin and at the interface between the resin and the material. However, for samples with few interconnections between cells or voids, these accessories are not effective since, due to the low permeability of the materials, the resin will penetrate only a surface layer, whose thickness depends on the sizes of the cells or voids.

2.3 Second Step: Series of Embeddings Alternated to Lapping. - The conventional technique of preparation of thin sections for optical microscopy involves, first, the preparation of one flat surface $( \pm 1 \mu \mathrm{m})$ by means of abrasives; then a glass slide is glued onto that surface and the specimens is thinned to $30 \mu \mathrm{m}$ by means of cutting, lapping and polishing. This procedure 
is absolutely not suitable for the specimens of pumice for three reasons. Firstly, the specimen will be contaminated by the abrasives since the surface of the pumice, which is not continuous for the presence of cells and voids, will trap the abrasive grains, especially those with fine grit (8001000-1200 mesh). Secondly, the preparation of a flat surface would be difficult for the presence of detached fragile material not completely embedded in resin. Finally, the thinner structures of the glassy framework of the pumice will fracture during lapping.

To avoid all these drawbacks we adopted a method based on the thinning of the sample by removing successively impregnated layers. The details of the procedure are:

i) the specimen block is gently cut, by means of a diamond wheel saw $350 \mu \mathrm{m}$ thick, into the form of a parallelepiped with sides of about $28 \times 46 \mathrm{~mm}^{2}$ (surface of the specimen) and a thickness of $20 \mathrm{~mm}$. One surface is embedded in resin; the specimen is then put under vacuum $\left(5 \times 10^{-3}\right.$ torr $)$ at a temperature of $80^{\circ} \mathrm{C}$ for $4-5 \mathrm{~min}$;

ii) a glass slice V1 $\left(28 \times 46 \times 1.8 \mathrm{~mm}^{3}\right)$, with function of support, is attached with araldit to the surface embedded in resin (Fig. 1a). After the polymerization the specimen is cut to a thickness of about $2 \mathrm{~mm}$ from the glass slide V1 by the diamond saw (Fig. 1b);

iii) a layer of resin is applied to the freshly cut surface;

iv) the specimen is thinned to about $500 \mu \mathrm{m}$ by means of a Riedoz (Besançon, France) mod. 73 diamond (600 mesh) grinding machine (Fig. 1c). This thickness is sufficient to prevent the propagation of fractures and modifications induced by the diamond saw and the grinding machine inside this kind of specimen in the thin layer ( $30 \mu \mathrm{m}$ thick) chosen for the various observations. This operation should be performed very gently (in about $10 \mathrm{~min}$ ) and carefully to avoid the fracture of the morphological structures of the sample;

v) another glass slide V2 is then applied to the surface prepared in iv), after resin embedding (Fig. 1d). This and the successive embeddings are performed with BY158 resin and relative hardener at a pressure of $5 \times 10^{-3}$ torr at $100^{\circ} \mathrm{C}$ for the maximum time this resin can resist before full polymerization takes place (about $10 \mathrm{~min}$ ). In this stage, the specimen, being thin, outgasses in a very short times; hence, it is possible to heat the resin at a temperature $\left(100^{\circ} \mathrm{C}\right)$ higher than when the specimen is thicker and the resin is heated at $80^{\circ} \mathrm{C}$ to have more fluidity. However, in any case, the specimen after the embedding and the glueing of the glass slide, is placed in a refrigerator cell at $2-4{ }^{\circ} \mathrm{C}$ to slow down the polymerization and hence to avoid volumetric deformations with breaking of the sample and/or of the glass slide support.

We have so obtained a sandwich with $500 \mu \mathrm{m}$ of specimen, embedded in resin, between two glass slides V1 and V2 (Fig. 1e). The problem of the fracture and loss of the fine glassy interconnections is avoided; the presence of micro-bubbles of air (1-20 $\mu \mathrm{m}$ in diameter) trapped in the resin is still observed;

vi) the presence of the micro-bubbles is reduced, initially, by thinning the specimen to $400 \mu \mathrm{m}$ by the Riedoz grinding machine. The machine grinds, firstly, the glass slide V1 (Fig. 1f). Then the procedure of embedding and thinning is successively repeated (Figs. 1g, h). At this time, for an effective reduction of the presence of air bubbles, the alternating embedding and thinning procedure is performed only for a few tens of $\mu \mathrm{m}$ (mean diameter of the micro-bubbles) at a time. This is the "key" of the thinning procedure; in fact, the probability of a complete penetration of the resin in the surface layer (which becomes closer and closer to the final specimen layer), increases by embedding and thinning the specimen in this way, successively, for many times. The time required for each of these lappings is about $30 \mathrm{~min}$.

vii) after $n$ embeddings ( $n \sim 10-15)$, the $\mathrm{V}_{n-1}$ glass slide is lapped away and the specimen thinned to $50 \mu \mathrm{m}$ by the Riedoz machine (Fig. 1i). Then the specimen surface is polished with $1000 \mathrm{mesh}$ abrasive paste to a thickness of about $45 \mu \mathrm{m}$ (Fig. 11). In this case neither contamination from the abrasive nor detachments of the fine glassy structures occur because the specimen is perfectly embedded and no cavities are present at the surface. 

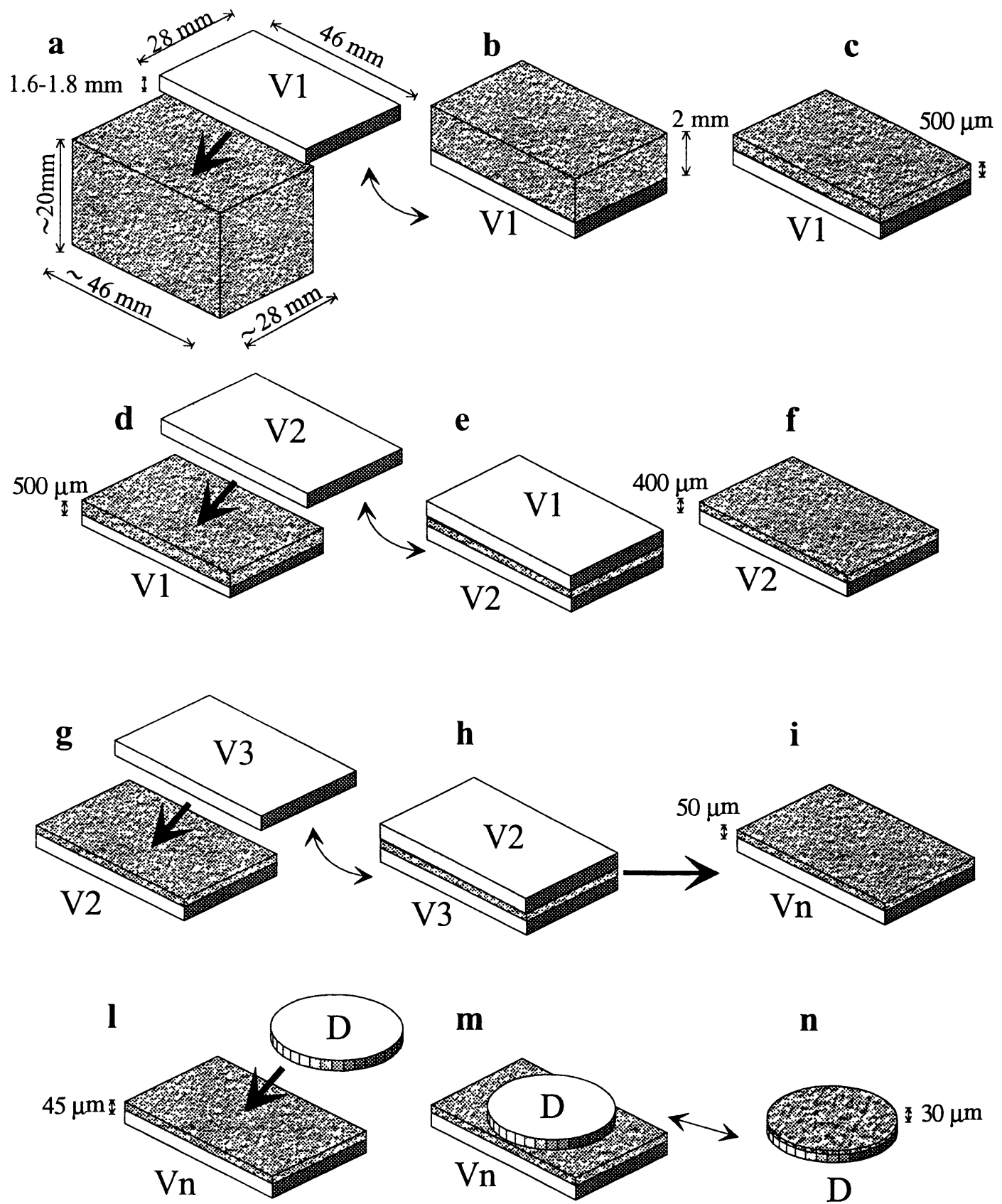

Fig. 1. - Schematic drawings of the various steps of the thinning procedure (series of embeddings alternated to lappings).

The polishing was performed either mechanically, by means of a Precision Lapping \& Polishing Machine LP30 of Logitech (Glasgow, Scotland, U.K.), or manually by using a glass plate support or a cast-iron polishing wheel. 
The specimen is then put in a ultrasonic bath for a few minutes in deionized water (to avoid chemical alterations) to remove the abrasive paste.

viii) a circular glass slide D, typical specimen support for both EPMA and SEM equipped with an analytical stage, and suitable for OM observations, is glued on the washed surface of the specimen (Figs. 11, m).

The glue must have a high mechanical strength and hardness to reduce the probability of detachment during the successive specimen thinning. The requirement of low viscosity is not necessary any more, since the surface does not present any irregularity of discontinuity and the bubble density is low. Araldit AW106 with hardener HV953U have proven to be the most suitable. The resin was fluidified at $150{ }^{\circ} \mathrm{C}$ on the glass disk $\mathrm{D}$. Then the disk was glued to the specimen and rapidly placed in a cold cell at $2-4^{\circ} \mathrm{C}$ for some hours to prevent rapid polymerization, which subsequently was performed at room temperature and atmospheric pressure for $24 \mathrm{~h}$.

2.4 Third Step: Final Preparation of the Specimen for the Various Observations. - After the glass disk $D$ has been glued onto the specimen surface, glass slide $V_{n}$ is lapped away with the Riedoz machine. The specimen is then thinned to $30 \mu \mathrm{m}$, either mechanically by the LP30 Logitech machine, or manually by the conventional lapping procedures (Fig. 1n). The final polishing is performed using the typical procedure required for quantitative EPMA analysis; in any case, it is advisable to operate very gently.

The time needed to produce simultaneously 25 final sections is about two weeks if the above mentioned automatic lapping and polishing devices are used.

\section{Discussion of Optical, SEM and EDS Analyses}

Several sections of pumices were investigated by optical microscopy, scanning electron microscopy and EDS microanalysis. The experimental parameters used, the results obtained and their discussion are reported in the following.

3.1 Experimental Methods of Observation and Analysis. - An Orthoplan Leitz (Wetzlar, Germany) and a M420 Wild (Heerbrugg, Switzerland) photo-optical microscopes were used for parallel and crossed polars observations.

Two Philips SEMs 515 electron microscopes equipped with EDAX 9900 and 9100 EDS detectors were employed for the morphological and microanalytical examinations of the samples. In addition, a backscattered electron (BSE) detector, whose geometry was especially designed for the detection of high angle BS electrons [7], was used in order to improve the atomic number contrast imaging $[8,9]$.

The standards of natural silicates and glasses were supplied by US National Museum of Natural History (USNM, Washington, DC, USA) [10] and Micro-Analysis Consultants (St. Ives, U.K.), as specified in Table II.

The quality of the analyses was checked by making frequent measurements on the reference standards while performing the analytical runs. In addition, cross-checks were made by using more than one standard.

The SEMs were operated at $30 \mathrm{kV}$ during the SE and BS observations. SEM-EDS was performed at $15 \mathrm{kV}$. The gun tungsten electron source was thermally conditioned for about $4 \mathrm{~h}$ in order to achieve a well-stabilized probe current of $2.000 \mathrm{nA}$ decreasing at a rate of $0.005 \mathrm{nA} \mathrm{h}^{-1}$. The analysis time was $120 \mathrm{~s}$. 
Table II. - Standards and elements used for the quantitative EDS microanalysis.

\begin{tabular}{|c|c|c|}
\hline Mineral & Oxides & $w t \%$ \\
\hline \multirow[t]{2}{*}{ Augite } & $\mathrm{SiO}_{2}$ & 50.73 \\
\hline & $\mathrm{CaO}$ & 15.82 \\
\hline \multirow[t]{2}{*}{ Wollastonite } & $\mathrm{SiO}_{2}$ & 50.92 \\
\hline & $\mathrm{CaO}$ & 47.99 \\
\hline \multirow[t]{3}{*}{ Anorthoclase } & $\mathrm{Na}_{2} \mathrm{O}$ & 9.31 \\
\hline & $\mathrm{SiO}_{2}$ & 66.44 \\
\hline & $\mathrm{Al}_{2} \mathrm{O}_{3}$ & 20.12 \\
\hline \multirow[t]{2}{*}{ Rhyolitic Glass } & $\mathrm{Na}_{2} \mathrm{O}$ & 3.75 \\
\hline & $\mathrm{SiO}_{2}$ & 76.71 \\
\hline \multirow[t]{5}{*}{ Basaltic Glass } & $\mathrm{Na}_{2} \mathrm{O}$ & 2.62 \\
\hline & $\mathrm{SiO}_{2}$ & 50.81 \\
\hline & $\mathrm{CaO}$ & 11.12 \\
\hline & $\mathrm{Al}_{2} \mathrm{O}_{3}$ & 14.06 \\
\hline & $\mathrm{FeO}$ & 11.84 \\
\hline Microcline & $\mathrm{K}_{2} \mathrm{O}$ & 15.14 \\
\hline \multirow[t]{3}{*}{ Ilmeńite } & $\mathrm{MnO}$ & 4.77 \\
\hline & $\mathrm{FeO}$ & 46.53 \\
\hline & $\mathrm{TiO}_{2}$ & 45.70 \\
\hline Fayalite & $\mathrm{FeO}$ & 67.55 \\
\hline \multirow[t]{2}{*}{ Olivine } & $\mathrm{MgO}$ & 49.42 \\
\hline & $\mathrm{FeO}$ & 9.55 \\
\hline
\end{tabular}

Quantitative SEM-EDS analyses were accomplished using the EDAX PVQUAN program, a modified version of the well-known FRAME-C NIST program [11], which corrects iteratively for background, peak overlapping and ZAF effects.

All the analysed elements were stable under the beam, except $\mathrm{Na}$. The $\mathrm{Na}$ intensity is underestimated by a few percent depending on the electron dose and the dose-rate, as already observed in previous studies [12].

Fig. 2. - Typical micrograph of a $30 \mu \mathrm{m}$ thick section of a pumice sample. The bubbles are distributed over regions where the average size of the bubbles is largely different. The preservation of glassy interconnections is good. a) Optical image, parallel polars; b) backscattered electron image and c) secondary electron image. Markers $=1 \mathrm{~mm}$. 

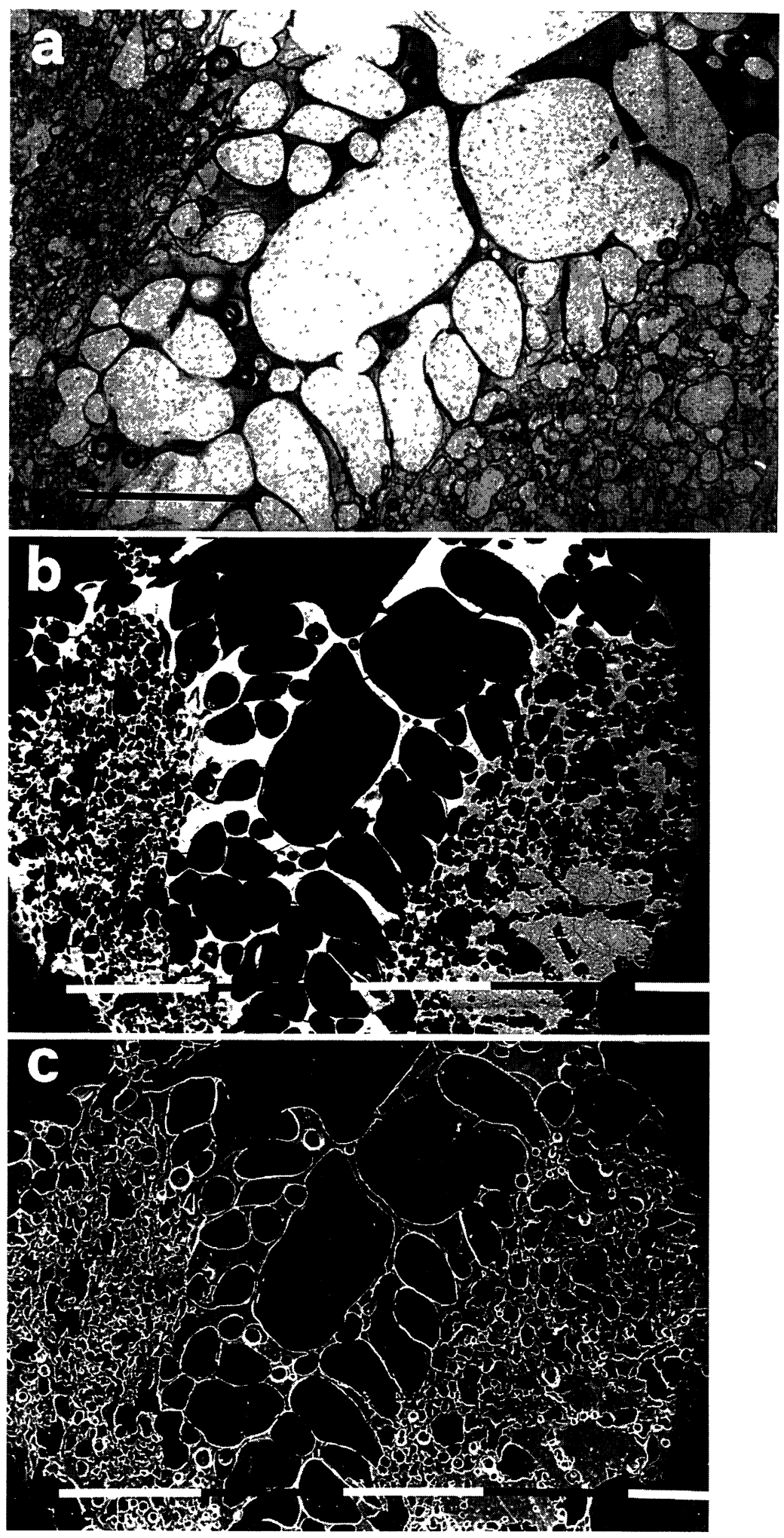

Fig. 2. 
3.2 ANALYSES. - Figure $2 \mathrm{a}$ is a typical optical micrograph, obtained with parallel polars, of a $30 \mu \mathrm{m}$ thick section of a pumice sample. Three features are to be noted:

i) it is possible to observe the preservation of most of the glass interconnections between the bubbles; only a few cracks or fractures are present;

ii) the size distribution of the gas bubbles and/or voids is very wide: bubbles with size of about $1 \mathrm{~mm}$ (at the centre of Fig. 2a) are seen together with bubbles of size down to micrometers;

iii) the glassy phase shows regions of different colours in transmitted light: a brown glass in the middle (where the bubbles are large) and a grey-white glass at the top-left and bottom-right corners (where the bubbles are small). In the black and white Figure $2 \mathrm{a}$ the brown glass appears dark grey and the resin filing the bubbles appears white.

Figure $2 \mathrm{~b}$ is a backscattered electron image, comprising the area of Figure $2 \mathrm{a}$ (at a slightly reduced magnification). Worth noting is the BSE signal coming from the glass in the centre of the image, which is higher than that produced by the glass situated at the edges. This means that the brown glass (as observed in OM), which surrounds the bigger bubbles in the center of the figure, has a higher mean atomic number composition with respect to that of the grey-white glass which surrounds the smaller bubbles at the edges. The embedding epoxy resin appears dark black, owing to its low mean atomic number.

Figure $2 \mathrm{c}$ is the secondary electron image of the same area. In this micrograph more details can be seen which provide information about the preservation of the interconnections and the choice of suitable areas for electron probe microanalysis on the basis of their flatness.

Figure $3 \mathrm{a}$ refers to a $30 \mu \mathrm{m}$ thick pumice specimen, different section from that of Figure 2, imaged with the transmitted light microscope set with parallel polars. The two-size distribution of the gas bubbles and the different contrast produced by the various regions of the glasses are apparent in this case too. Almost all the thin glass interconnections have been preserved during the thinning procedure. The presence of small gas bubbles and/or inclusions (about $10 \mu \mathrm{m}$ in diameter and indicated as B in the figure) should be noted. They are located underneath the specimen surface and visible with transmitted light and with BSE, when close to the surface.

Figures $3 b$ and $3 c$ are the BSE and SE images respectively of the same area presented in Figure 3a. In these images the previously observed inclusions B are not nearly as visible since the electrons producing the signals come from higher levels than those where the inclusions or bubbles are situated. However, they will be within the X-ray generation volume and their composition detectable. The regions of this kind of specimens useful for quantitative electron probe microanalysis can therefore be chosen only after both optical microscopy and scanning electron microscopy observations have been performed.

Fig. 3. - Micrograph of a different section of the same pumice sample as for Figure 2, at higher magnification, confirming the two distribution of the bubble size. a) Optical image (parallel polars) showing inclusions, $\mathrm{B}$, underneath the surface; $b$ ), c), backscattered and secondary electron images. The inclusions are not visible, demonstrating their location below the surface. Markers $=100 \mu \mathrm{m}$. A few air bubbles are trapped in the resin (e.g. A); they act as divergent lenses for the light and appear dark in the optical micrograph; owing to the low density the air bubbles are not visible with BSE, whereas a strong edge contrast is seen with SE, as expected for a structure very close to the surface. 

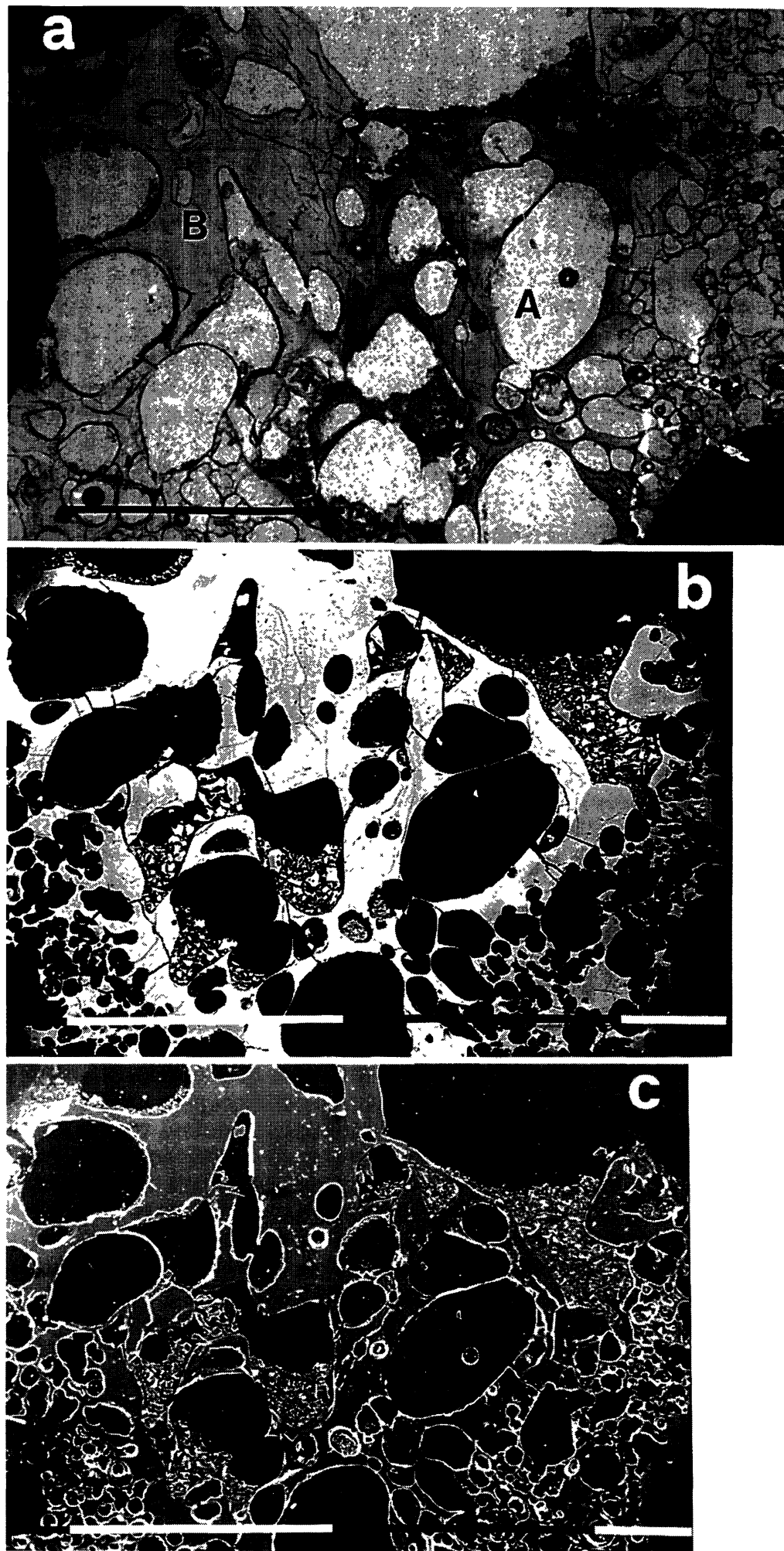

Fig. 3. 
Table III. - EDS microanalysis of type $A$ and B glasses in wt\%. Each analysis is the average of ten different analyses taken from the two glasses shown in Figure 2.

\begin{tabular}{|c|c|c|}
\hline Oxides & $\begin{array}{c}\text { Type A (brown) } \\
\text { (basaltic-andesite) }\end{array}$ & $\begin{array}{c}\text { Type B (grey-white) } \\
\text { (dacite) }\end{array}$ \\
\hline $\mathrm{SiO}_{2}$ & 55.94 & 65.15 \\
$\mathrm{Al}_{2} \mathrm{O}_{3}$ & 11.31 & 18.61 \\
$\mathrm{FeO}$ & 12.59 & 0.31 \\
$\mathrm{MnO}$ & 0.39 & - \\
$\mathrm{MgO}$ & 1.12 & 0.12 \\
$\mathrm{CaO}$ & 5.67 & 0.20 \\
$\mathrm{Na}_{2} \mathrm{O}$ & 5.28 & 7.31 \\
$\mathrm{~K}_{2} \mathrm{O}$ & 3.31 & 6.39 \\
$\mathrm{TiO}_{2}$ & 1.01 & - \\
\hline $\mathrm{Tot}$ & 96.62 & 98.09 \\
\hline
\end{tabular}

Table III reports the mean composition of the two different glasses (indicated as type A and B) selected for their extreme Fe contents. The mean composition was found from ten analyses for each glass. The microanalyses were performed in the brown glass (type A), in the centre of Figure 2, and in the grey-white glass (type B) visible at the border of Figure 2, taking into account the presence of inclusions and glass bubbles underneath the surface. The main point of interest is that type A-glass is an iron-rich glass (up to about $12 \mathrm{wt} \%$ as $\mathrm{FeO}$ ), whereas type B-glass is almost an iron-free glass (about $0.3 \mathrm{wt} \%$ ).

As for the other elements, type A-glass is richer in $\mathrm{CaO}$ (about $6 \mathrm{wt} \%$, against a $0.2 \mathrm{wt} \%$ of type $\mathrm{B})$ and, in general, in all the divalent cations $(\mathrm{MnO}, \mathrm{MgO})$ and $\mathrm{TiO}_{2}$. In contrast, it is poorer in alkali $\left(\mathrm{Na}_{2} \mathrm{O}\right.$ and $\mathrm{K}_{2} \mathrm{O}$ ). Moreover, type A-glass is much poorer in $\mathrm{Al}_{2} \mathrm{O}_{3}$ (about $11 \mathrm{wt} \%$ ) and $\mathrm{SiO}_{2}$ (about $56 \mathrm{wt} \%$ ) compared to type B-glass which contains about $19 \mathrm{wt} \%$ of $\mathrm{Al}_{2} \mathrm{O}_{3}$ and about 65 wt \% of $\mathrm{SiO}_{2}$. Both glasses are hydrated, with few percent of $\mathrm{H}_{2} \mathrm{O}$ by weight. Type A-glass is a typical basaltic-andesitic glass, whereas type B-glass is a dacitic glass. Intermediate concentrations were also found in other sections of the same material.

These microchemical analyses provide an explanation for the high BSE signal coming from the type A-glass in respect to type B, since the mean atomic number of the first glass is higher than that of the second type. The brown colour of the glass in the optical micrographs depends from the iron content, too.

The different size distribution of the gas bubbles in the two kinds of glasses arises from the different geochemistry and can be understood by assuming an interference between fluids of different composition which maintain their viscosity characteristics; the latter depends on the temperature and the $\mathrm{SiO}_{2}$ content. This assumption is strongly suggested by the presence of clearly defined 


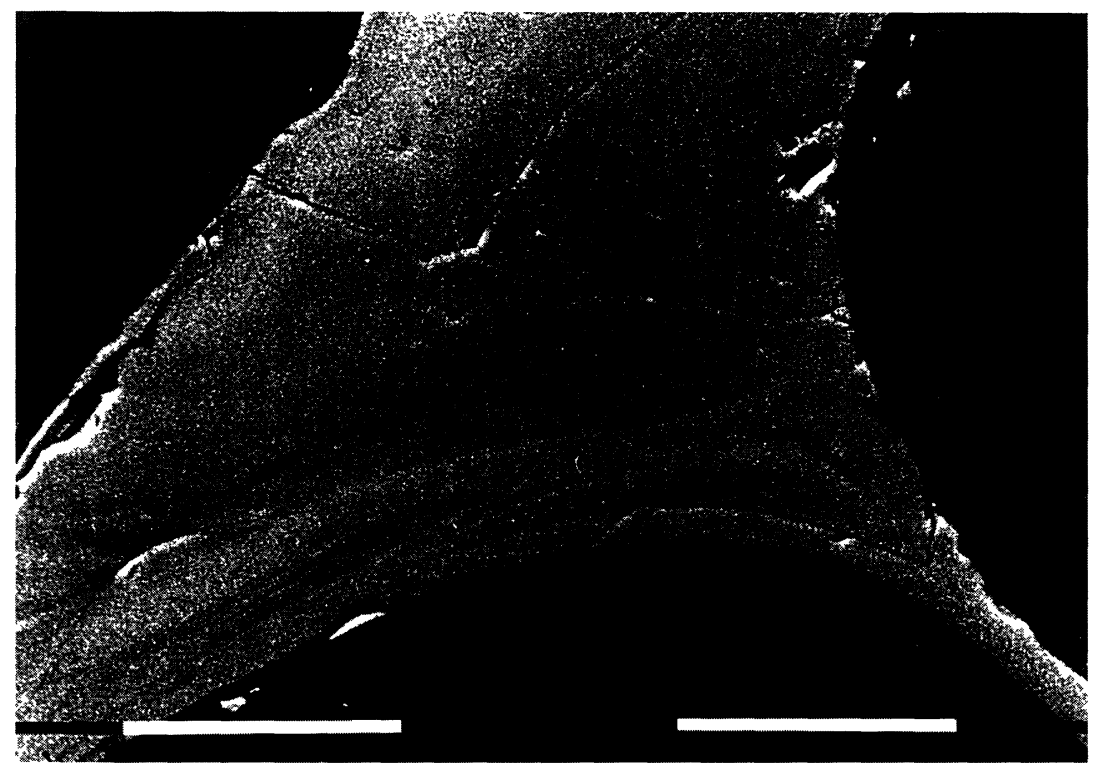

Fig. 4. - BSE image of a detail of a glass junction between three gas bubbles. Various bands (few micrometers thick) are visible. They run almost parallel the bubble boundaries and mix together. Marker $=$ $10 \mu \mathrm{m}$.

interfaces between the glasses having different vesicular textures (Figs. 2,3).

Figure 4 is a BSE image of a detail of a glass junction between three gas bubbles. Various bands (a few micrometers thick) running almost parallel to the bubble boundaries and mixing together are visible. The presence of these bands is a further confirmation of the fact that the two volcanic fluids came into contact. In addition, the existence of bands suggests the fluids partially mixed with each other and cooled very rapidly before they could homogenize.

\section{Conclusions}

The present paper presents:

i) a method of specimen preparation of porous, brittle and low permeability materials to be used for both optical microscopy (OM), scanning electron microscopy (SEM) and electron probe microanalysis (EPMA);

ii) the results of the successful application of the above method to the analysis of samples of pumices (which are pyroclastic rocks produced by the violent expulsion of magmatic material in the air during the first stages of explosive volcanism involving large amounts of gases).

Large, polished areas (about $400 \mathrm{~mm}^{2}$ ) of consistent pumice-like rocks were prepared. Previous observations referred to incoherent glassy material, where the micro-chemical correlation with morphology was lost. The present method avoids the breaking of the glassy interconnections, allows the filling of the majority of the bubbles and voids with resin and produces flat surfaces suitable for optical, SEM and EPMA investigations. 
They have shown that some pumices from Linosa contain two types of glasses with different composition. The information obtained from the knowledge of the crystal-chemistry and habit on a micro-scale suggests that the two types of magma came into contact, partially mixed and cooled very rapidly before they could homogenize.

The above method has been successfully applied also to the preparation of other low permeability and high porosity materials such as sedimentary rocks, synthetics and biomaterials (synthetic phosphates, carbonates and bones). This method, associated with cryofixing and cryosubstitution techniques, can be applied also to samples of rocks containing fine clay particles (not lithified). Details of these results will be published in a forthcoming paper.

\section{Acknowledgements}

This work was supported by Consiglio Nazionale delle Ricerche, CNR - Rome (Holder, Prof. P.L. Rossi) and MURST, Rome.

\section{References}

[1] Awadallah S.H., J. Sedim. Petrol. 61 (1991) 632-633.

[2] Kuehl S.A., Nittrouer C.A. and DeMaster D.J., J. Sedim. Petrol. 58 (1988) 12-23.

[3] Crevello P.D., Rine J.M. and Lanesky D.E., J. Sedim. Petrol. 51 (1981) 658-660.

[4] Conway J.S., J. Sedim Petrol. 52 (1982) 650-651.

[5] Jim C.Y., J. Sedim. Petrol. 55 (1985) 597-599.

[6] McNeil B. and Morris E., Mineral. Mag. 56 (1992) 120-122.

[7] Reimer L. and Volbert B., Philips Electron Opt. Bull. 118 (1982) 6.

[8] Reimer L., Scanning Electron Microscopy (Springer-Verlag Berlin, 1985) p. 45.

[9] Newbury D.E., Joy D.C., Echlin P., Fiori C.E. and Goldstein J.I., Advanced Scanning Electron Microscopy and X-Ray Microanalysis (Plenum Press, New York, 1987).

[10] Jarosewich E., Nelsen J.A. and Norberg J.A., Geost. Newsletter 4 (1980) 43.

[11] Myklebust R.L., Fiori C.E. and Heinrich K.F.J., Frame-C: a Compact Procedure for Quantitative Energy-Dispersive Electron Probe X-Ray Analysis, National Bureau of Standards Technical Note No. 1106, US Government Printing Office, Washington, DC (1979) p. 106.

[12] Valdrè G., X-Ray Spectrometry 23 (1994) 120-124. 